\title{
Sex disparities in thyroid cancer: a SEER population study
}

\author{
Peng Li ${ }^{1 \#} \wedge$, Ying Ding ${ }^{1 \#}$, Mengyuan Liu ${ }^{1}$, Wenlong Wang ${ }^{1,2}$, Xinying $\mathrm{Li}^{1,2}$ \\ ${ }^{1}$ Thyroid Surgery Department, Xiangya Hospital, Central South University, Changsha, China; ${ }^{2}$ National Clinical Research Center for Geriatric \\ Disorders, Xiangya Hospital, Central South University, Changsha, China \\ Contributions: (I) Conception and design: W Wang, P Li, Y Ding; (II) Administrative support: X Li; (III) Provision of study materials or patients: P \\ Li, Y Ding; (IV) Collection and assembly of data: P Li, Y Ding; (V) Data analysis and interpretation: Y Ding, P Li, M Liu; (VI) Manuscript writing: \\ All authors; (VII) Final approval of manuscript: All authors. \\ "These authors contributed equally to this work. \\ Correspondence to: Wenlong Wang, PhD; Xinying Li, PhD. Thyroid Surgery Department, National Clinical Research Center for Geriatric Disorders. \\ Xiangya Hospital, Central South University. No. 87 Xiangya Road, Changsha 410008, China. Email: 2269132213@qq.com; lixinyingcn@126.com.
}

\begin{abstract}
Background The incidence and mortality of thyroid cancer vary based on race as well as gender. Both gender thyroid cancer patients give variable clinical characteristics, such as tumor size and distant metastasis. However, sex differences in the prognosis of thyroid cancer remain controversial. Therefore, the present study explored the relationship between gender and prognosis of patients with thyroid cancer for conducive personalized treatment.
\end{abstract}

Methods: A retrospective analysis was carried out on patients with pathologically proven thyroid cancer from the Surveillance, Epidemiology, and End Results (SEER) database. The gender disparities in the prognosis of different cohorts, derived by propensity score matching were investigated using Cox proportional hazards models and Kaplan-Meier curves.

Results: Among the studied 41,270 female and 13,188 males with thyroid cancer, gender was an independent prognostic factor for overall (OS) and cancer-specific (CSS) survival (HR =1.632, 95\% CI: 1.499-1.777, $\mathrm{P}<0.001 ; \mathrm{HR}=1.473$, 95\% CI: 1.245-1.741, $\mathrm{P}<0.001)$. Though, male patients had a larger tumor size $(17.4$ vs. $23.5 \mathrm{~cm})$ and a larger proportion of metastasis [lymph nodes (LNs): 33.2\% vs. 21.0\%; distant: $2.3 \%$ vs. $0.9 \%$ ], female had a higher incidence and earlier age diagnosis with thyroid cancer (48.0 vs. 52.5 years old). Survival Time (in months) of male patients was also significantly lower than female patients (72.4 vs. 76.8 months). In the Kaplan-Meier curves of cohorts derived by propensity score matching, OS and CSS declined much sharply for male $(\mathrm{P}<0.001)$. The mean number $(2.0$ vs. 4.0$)$ and mean ratio $(0.192$ vs. 0.297) of positive nodes supported worse prognosis for male patients. Whereas factors including race, age, surgery, histology recodes, T, N, M stage and combined summary stage affected the CSS of male and female patients, however plus median income had an extra impact on male population $(\geq \$ 55,000$ vs. $<\$ 55,000$ : HR $=0.739,95 \%$ CI: $0.574-0.953, \mathrm{P}=0.020)$.

Conclusions: Our study demonstrated that male patients had a prognostic factor for poorer OS and CSS. Other factors including race, age, income, histological type, surgery, T, N, M stage influenced OS of male and female thyroid cancer patients. Interestingly, race had no impact on CSS of thyroid cancer patients, whereas median income affected only the male patients CSS.

Keywords: Thyroid cancer; sex disparities; Surveillance, Epidemiology, and End Results (SEER)

Submitted Aug 10, 2021. Accepted for publication Nov 05, 2021.

doi: $10.21037 / g s-21-545$

View this article at: https://dx.doi.org/10.21037/gs-21-545

$\wedge$ ORCID: 0000-0001-8176-7470. 


\section{Introduction}

The incidence of thyroid cancer has increased in the last few decades. In the United States alone, thyroid cancer accounts for $2.9 \%$ of new occurrence and more than $90 \%$ of endocrine cancer cases (1). Thyroid cancer ranks as the fifth most common cancer in American females (2). Additionally, in recent years, the increase in the thyroid cancer incidence among people aged 15-39 years has also increased (3). However, despite the high incidence of thyroid cancer, its mortality remains comparatively low and remains stable. In the United States, mortality associated with thyroid cancer was stable between 1975 and 2009 (about 0.5 deaths per 100,000 people) (4). However, incidence-based mortality increased $1.1 \%$ per year between 1974 and 2013 (5). Thyroid carcinoma has four main types, viz. papillary thyroid carcinoma (PTC), medullary thyroid carcinoma (MTC), follicular thyroid carcinoma (FTC), and anaplastic thyroid carcinoma (ATC). Its noteworthy that PTC and FTC account for over $95 \%$ of all thyroid cancers diagnosed annually (6). However, patients with these two types of cancer have a great 5-year survival (>98\%) (7). Although MTC and ATC are rare, they are aggressive in nature and progress rapidly, becoming the main cause of death in patients with thyroid cancer. Unfortunately, the 5 -year survival of patients with ATC ranges from $0 \%$ to $10 \%$, while the median survival is only 5-6 months (8).

The incidence and mortality in thyroid cancer vary between different races and the sex. Studies showed that the incidence of thyroid cancer in whites were considerably higher than other racial groups such as blacks, Asians, and Hispanics (9). Importantly, well-differentiated thyroid cancer was 3 times more common in females, while the incidence of poorly differentiated thyroid cancer in males and females were similar (10). In addition, male and female thyroid cancer patients had differences in clinical characteristics, such as tumor size and histological type (11). Although, Wang et al. found that sex was not an independent risk factor for distant metastasis $(12,13)$, but sex differences in the prognosis of thyroid cancer remains controversial. Further, a meta-analysis showed that the prognosis of male PTC patients was worse, and the risk of recurrence was 1.53 times that of females (14). Besides, Bian et al. and Liu et al. found that in PTC, male patients had a poorer prognosis than female patients $(15,16)$. Likewise, Kruijff et al. demonstrated that the risk of structural recurrence in men was 2.44 times that of women (17). On the contrary, Nilubol et al. reported that sex does not constitute as an independent prognostic factor for diseasespecific survival in thyroid cancer (18). Meanwhile, Oyer et al. and Grogan et al. also reported the similar findings $(19,20)$ and there was no significant sex difference in the prognosis of ATC patients (8).

These conflicting results pose problem for the treatment and management of thyroid cancer patients. If male gender has poor prognostic factor in thyroid cancer, then more aggressive treatment (such as total thyroidectomy and LN dissection followed by radioactive iodine ablation) should be considered for men. Therefore, we explored in larger cohort with longer follow-up time to assess if sex differences existed in the prognosis of thyroid cancer.

We present the following article in accordance with the STROBE reporting checklist (available at https://dx.doi. org/10.21037/gs-21-545).

\section{Methods}

\section{Data selection}

The SEER database, covering approximately $28 \%$ of the US population, is the largest publicly available cancer database (21). Patients with thyroid cancer were recruited retrospectively (primary site coded as C73.9-thyroid gland) between 2004 and 2018 from the SEER database: Incidence - SEER Research Data, 9 Registries, Nov 2020 Sub (1975-2018). Patient characteristics (including age, sex, race, year of diagnosis, surgery status), tumor characteristics (including tumor laterality, histological types, tumor size, AJCC TNM stage, SEER summary stage, regional LNs) and survival information were obtained from the database. According to the latest version of AJCC staging (22), patients were divided into two subgroups based on the (younger and older than 55 years old). The annual income parameter was also introduced into our study, as it reflects the access to healthcare.

In this large cohort, microscopic-confirmed thyroid cancer patients with histological types limited to differentiated thyroid carcinoma and medullary carcinoma according to AYA site recode 2020 Revision (in which status of differentiation such as poorly differentiated and anaplastic thyroid cancer was not mentioned) were included. Data on regional LNs were also included. Patients lacking the positive microscopic confirmation $(n=1,683)$, exact histological type $(n=1,693)$, combined summary stage $(n=490)$, exact value of age $(n=453)$, race $(n=857)$, AJCC TNM ( $n=37)$, surgery status $(n=184)$, tumor size $(n=1,972)$ 

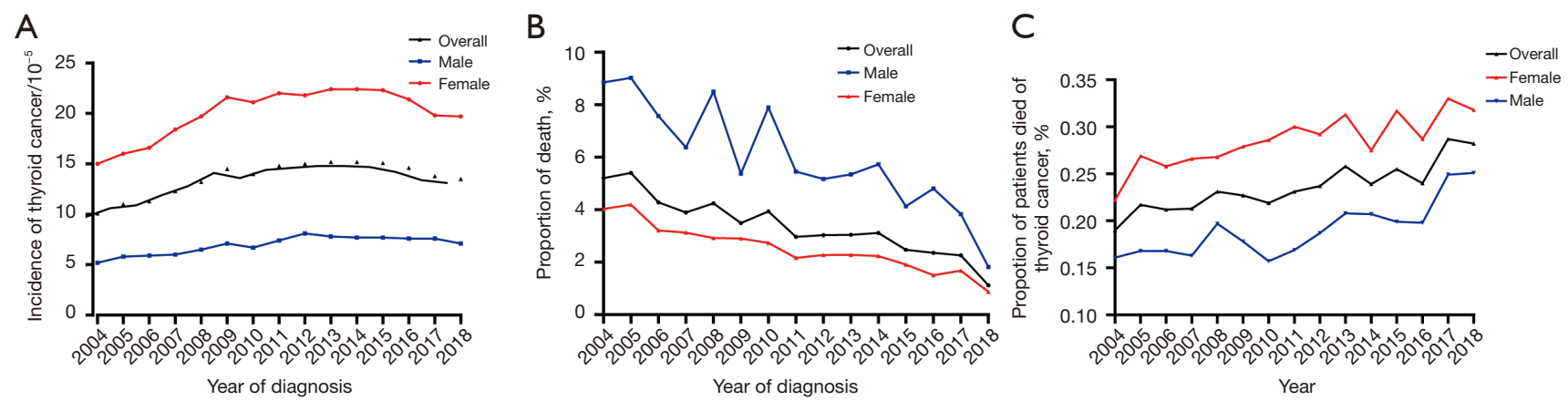

Figure 1 Epidemiological differences between male and female patients with thyroid cancer from SEER database. (A) Overall, female and male patients age adjusted incidence of thyroid cancer shown for 1 year period between 2004 and 2018. (B) Proportion of death in overall, female and male patients diagnosed with thyroid cancer from 2004 to 2018. (C) Proportion of patients died from thyroid cancer.

and annual income $(\mathrm{n}=4)$ were excluded from the study (Figure S1). The data was re-staged for all the patients according to the 7th AJCC T/N/M staging system to avoid any conflict $(22,23)$. We investigated the epidemiological differences between male and female patients based on data from SEER*stat 3.8.9. Proportion of death is defined as the contribution of thyroid-cancer-specific deaths in incident cases. Proportion of patients died of thyroid cancer is defined as the ratio of thyroid-cancer-specific deaths to dead population of the year.

\section{Statistical analyses}

Continuous variables are presented as means (with standard deviation), whereas the categorical variables are described as frequencies and percentages, compared using $t$-test and Pearson's chi-squared test, respectively. Univariable and multivariable survival analyses using Cox proportional hazards models was used to calculate the hazard ratios (HRs), for estimating the impact of variables of interest on survival. Further, survival curves were derived by Kaplan-Meier method and compared using log-rank test. To eliminate any possible selection bias in this observational non-randomized controlled trials, male and female patients diagnosed with thyroid cancer between 2004 and 2018 were matched via PSM (24). Additionally, to confirm our conclusion on different levels, we performed several matchings including different factors such as race, age, tumor size, SEER summary stage, histological type and surgery status. All of the statistical analyses were carried out using SPSS Statistical Software version 22.0 (IBM Corp., USA), where a two-sided P value $(<0.05)$ was considered statistically significant.

\section{Ethical statement}

The study was conducted in accordance with the Declaration of Helsinki (as revised in 2013).

\section{Results}

\section{Baseline characteristics of the SEER cohort}

During the time of 1975-2018, the age-adjusted incidence of thyroid cancer was 9.2 (4.9 in male, 13.3 in female) per 100,000, whereas from 2010 to 2016, the incidence was at a stable level. Female were affected 3 times more than male, although the curves were shifting downward during 20172018 (Figure 1A). Male patients diagnosed with thyroid cancer each year, had higher potential of specific death (Figure 1B). Whereas the proportion of patients died due to thyroid cancer among all mortality also risen (Figure 1C). Thus, thyroid cancer remains threat to human health, especially for female due to the higher incidence.

In total patients, 41,270 female and 13,188 male patients (female to male ratio was 3.13 ) were retrospectively recruited from the SEER database (Table 1). Female patients were typically diagnosed at an earlier age than the males (female $48.0 v s$. male 52.5 years old). At the ethnic level, both the male and female white population were affected (79.8\% in female and $84.6 \%$ in male patients, $\mathrm{P}<0.001$ ). Although compared with female, male patients had larger tumor size (female $17.4 v s$. male $23.5 \mathrm{~cm}, \mathrm{P}<0.001$ ), larger proportion of $\mathrm{LN}$ metastasis (male $33.2 \% v s$. female $21.0 \%$, $\mathrm{P}<0.001$ ) and distant metastasis (male $2.3 \% v s$. female $0.9 \%$, $\mathrm{P}<0.001)$ at the time of diagnosis with thyroid cancer. The observed profile was consistent with the distribution of combined summary stage (regional metastasis: $36.1 \%$ male 
Table 1 Baseline characteristics of the SEER cohort [patients with thyroid cancer from the SEER database (2004-2018)]

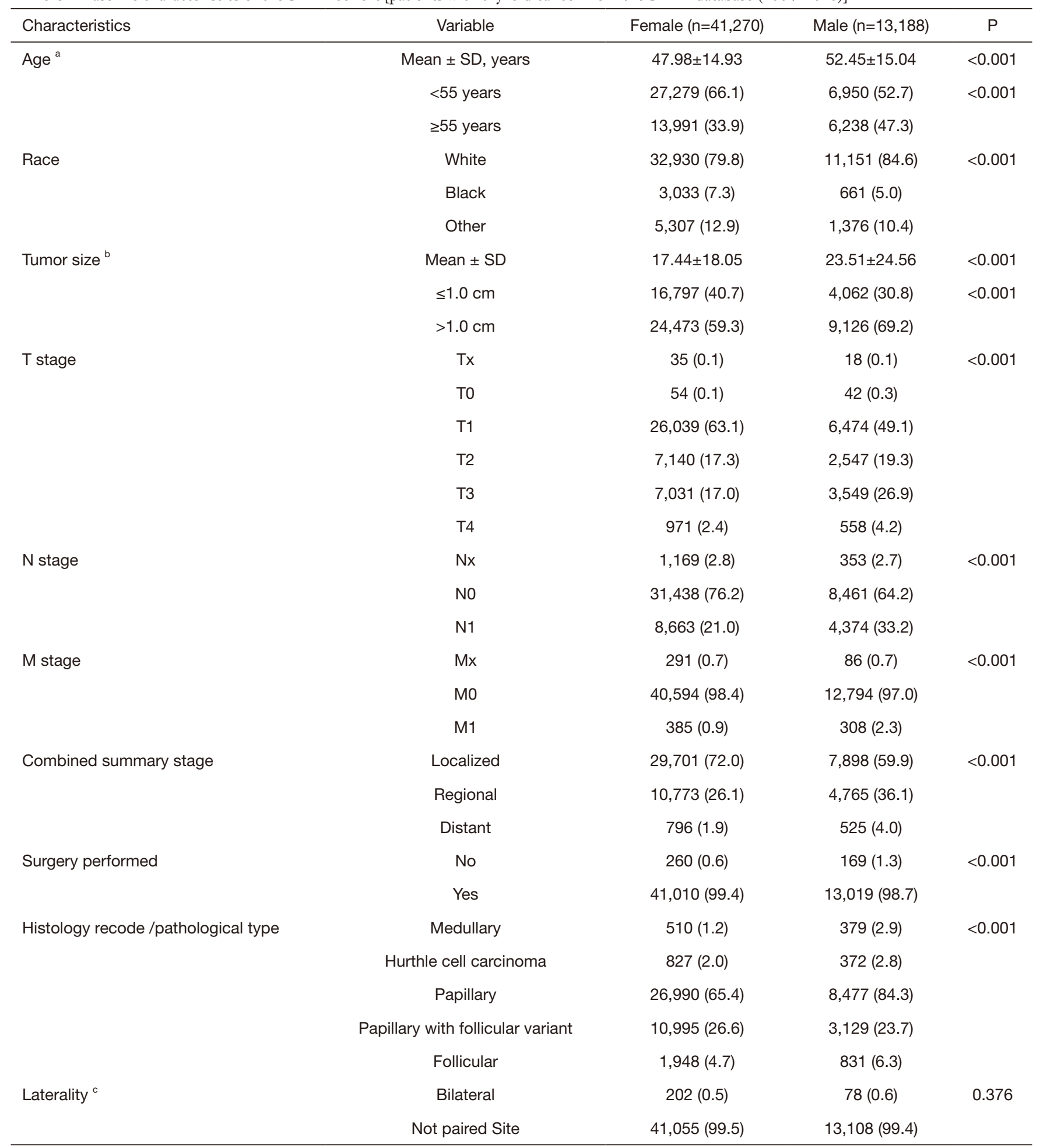

Table 1 (continued) 
Table 1 (continued)

\begin{tabular}{|c|c|c|c|c|}
\hline Characteristics & Variable & Female $(n=41,270)$ & Male $(n=13,188)$ & $P$ \\
\hline \multirow{3}{*}{ Median income } & $\$ 35,000-\$ 54,999$ & 6,308 (15.3) & $1,900(14.4)$ & \\
\hline & $\$ 55,000-\$ 74,999$ & 18,693 (45.3) & $5,831(44.2)$ & \\
\hline & $\geq \$ 75,000$ & $16,148(39.1)$ & $5,413(41.0)$ & \\
\hline All-cause death & Dead & $2,134(5.2)$ & $1,457(11.0)$ & \\
\hline \multirow[t]{2}{*}{ Cancer-specific death } & Alive & 40,817 (98.9) & $12,810(97.1)$ & $<0.001$ \\
\hline & Dead & $453(1.1)$ & $378(2.9)$ & \\
\hline Survival time (in month) & Mean \pm SD & $76.8 \pm 49.59$ & $72.39 \pm 49.25$ & $<0.001$ \\
\hline
\end{tabular}

Data are presented as mean \pm SD or $n(\%)$. ${ }^{a}$, age at diagnosis was grouped into $<55$ and $\geq 55$ years old based on the 8 th AJCC staging system; ${ }^{b}$, tumor size was grouped into $\leq 1.0$ and $>1.0 \mathrm{~cm}$ based on the definition of micro-thyroid carcinoma; ${ }^{c}$, the laterality of where the thyroid cancer originated.

vs. $26.1 \%$ female, $\mathrm{P}<0.001$, distant metastasis: $4.0 \%$ male vs. $1.9 \%$ female, $\mathrm{P}<0.001)$. A rare pathological type, medullary carcinoma, occurred more frequently in male than in female patients (male $2.9 \%$ vs. female $1.2 \%, \mathrm{P}<0.001$ ). Male patients' survival time (in months) was significantly lower than female patients (male 72.4 vs. female 76.8 months, $\mathrm{P}<0.001)$. However, thyroid cancer caused more specific death $(2.9 \%$ vs. $1.1 \%, \mathrm{P}<0.001)$ of male patients. We found sex differences in whether surgery was performed or not (surgery performed Male:Female $=98.7 \%: 99.4 \%, \mathrm{P}<0.001$ ) which might be attributed to tumor progression and malignancy. Median income was also different in females and males $(\mathrm{P}<0.001)$. But the difference between the laterality of male and female patients was non-significant $(\mathrm{P}=0.376)$. These findings revealed a significant sex disparity in clinical characteristics of thyroid cancer.

\section{Overall survival (OS) in men was significantly lower compared to women}

As showed in Kaplan-Meier analysis of the SEER cohort, OS declined more sharply for male (Log-rank test, $\mathrm{P}<0.001$ ) (Figure 2A). Similar results were observed for CSS (Logrank test, $\mathrm{P}<0.001$ ) (Figure $2 B$ ). Namely, female patients had better OS and CSS prognosis compared with the male. In the univariable and multivariable analyses of OS and CSS in the SEER cohort, there was a significant difference between males and females with different tumor sizes, ages, or median income subgroups. The male $v s$. female HRs were
$>1.000$ (Tables S1,S2).

Additionally, the mean number of positive nodes was 2.0 in female patients, whereas the mean number of positive nodes was 4.0 in male patients. Nodal ratio (NR) is defined as the number of positive LNs out of the total LNs in the specimen. Mean NR were 0.20 in female patients and 0.30 in male patients, respectively (Table S3).

\section{Differences in the survival of female and male patients in cohorts after propensity score matching}

After 1:1 matching, including all the factors, 12,779 male and 12,779 female patients were collected to form a new post-PSM cohort (Table S4). Survival time were longer $(74.1 \pm 49.1$ vs. $72.7 \pm 49.2, \mathrm{P}=0.018)$ in the female patients. There is more overall and specific death in male (overall death: $10.6 \%$ vs. $6.9 \%$, specific death: $2.5 \%$ vs. $1.9 \%$, $\mathrm{P}<0.001$, respectively).

Kaplan-Meier curves of OS and CSS for male and female patients in the post-PSM cohort supported the same conclusion as the SEER cohort (Figure $3 A, 3 B$ ). And the results remained significant in matching for individual factors and other combinations thereof (Figure S2). Compared with female patients, the HR for all-cause death in male patients was 1.62 (95\% CI: 1.514-1.734, $\mathrm{P}<0.001)$, and the HR for cancer-specific death was 1.44 (95\% CI: 1.248-1.654, $\mathrm{P}<0.001$ ) (Table 2). After adjustment for clinical basic data, these HRs for all-cause and cancer-specific death became 1.63 (95\% CI: $1.499-$ 

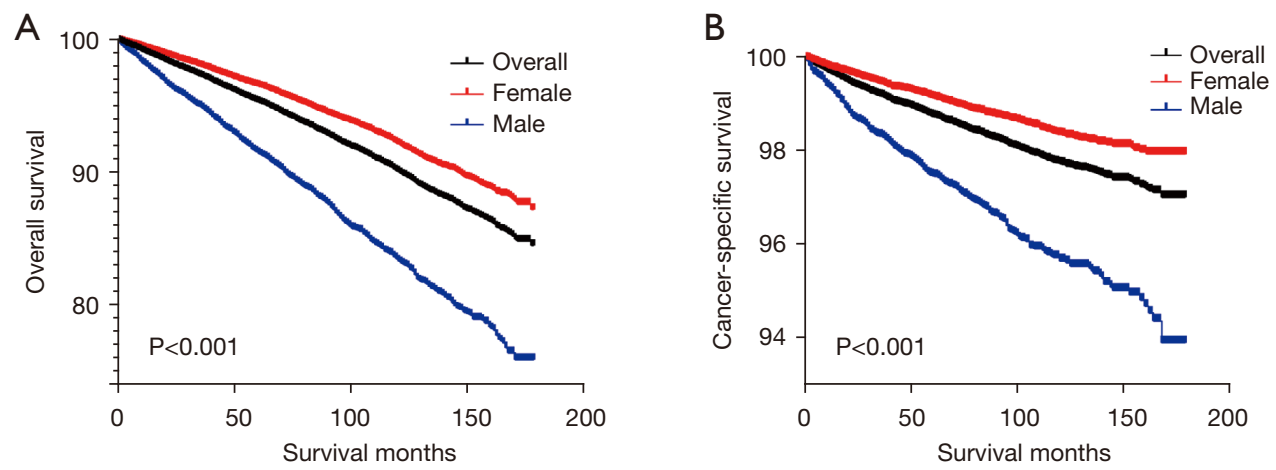

Figure 2 Kaplan-Meier curves of the SEER cohort. Overall survival (A) and cancer-specific survival (B) in all, female, and male thyroid cancer patients.
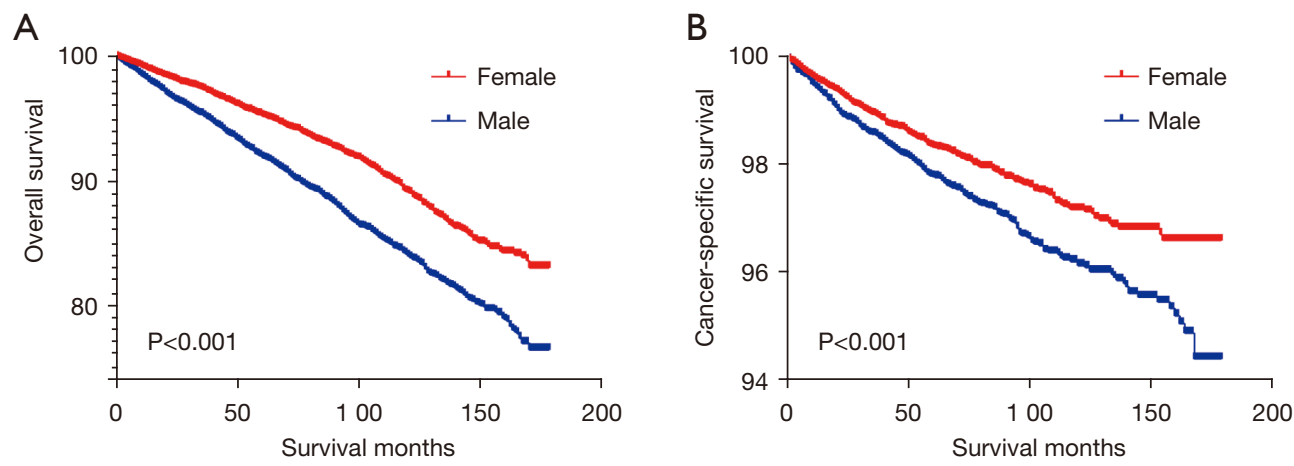

Figure 3 Kaplan-Meier curves of the post-PSM cohort. All the factors (except for laterality in Table 1) with an impact on the survival prognosis were included in matching. Baseline characteristics were shown in supplementary material. Overall survival (A) and cancer-specific survival (B) curves for female and male patients with thyroid cancer in the post-PSM cohort, log-rank test, $\mathrm{P}<0.001$, respectively.

Table 2 Hazard ratios of sex for all-cause death and cancer-specific death of thyroid cancer

\begin{tabular}{|c|c|c|c|c|c|c|c|c|}
\hline \multirow{3}{*}{ Sex } & \multicolumn{4}{|c|}{ Unadjusted } & \multicolumn{4}{|c|}{ Adjusted } \\
\hline & \multicolumn{2}{|c|}{ All-cause death } & \multicolumn{2}{|c|}{ Cancer-specific death } & \multicolumn{2}{|c|}{ All-cause death } & \multicolumn{2}{|c|}{ Cancer-specific death } \\
\hline & $\mathrm{HR}(95 \% \mathrm{Cl})$ & $P$ value & $\mathrm{HR}(95 \% \mathrm{Cl})$ & $P$ value & $\mathrm{HR}(95 \% \mathrm{Cl})$ & $P$ value & HR (95\% Cl) & $P$ value \\
\hline Female & 1 (reference) & $<0.001$ & 1 (reference) & $<0.001$ & 1 (reference) & $<0.001$ & 1 (reference) & $<0.001$ \\
\hline Male & $1.62(1.514-1.734)$ & & $1.44(1.248-1.654)$ & & $1.63(1.499-1.777)$ & & $1.47(1.245-1.741)$ & \\
\hline
\end{tabular}

1.777, $\mathrm{P}<0.001)$ and $1.47(95 \% \mathrm{CI}: 1.245-1.741, \mathrm{P}<0.001)$

(Table 2), respectively.

\section{Prognostic factors for thyroid cancer in men and women}

The statistically significant factors affecting OS of female thyroid cancer (Table 3 and Table S5) were race (white $v s$. black: $\mathrm{HR}=0.74,95 \%$ CI: $0.636-0.852, \mathrm{P}<0.001$, other vs. black: $\mathrm{HR}=0.68,95 \% \mathrm{CI}: 0.565-0.822, \mathrm{P}<0.001)$, age of diagnosis $(<55$ vs. $\geq 55$ years old: $\mathrm{HR}=6.20,95 \%$ CI: 5.612-6.838, $\mathrm{P}<0.001)$, median income $(\geq \$ 55,000$ vs. $<\$ 55,000:$ HR $=0.84,95 \%$ CI: $0.753-0.940, \mathrm{P}<0.001$ ), surgery (versus not performed: HR $=0.13,95 \%$ CI: $0.108-$ $0.167, \mathrm{P}<0.001$ ), distant in combined summary stage (versus localized: $\mathrm{HR}=2.13,95 \% \mathrm{CI}: 1.671-2.723, \mathrm{P}<0.001)$, T stage, $M$ stage and histology recodes (versus medullary: HR 
Table 3 Multivariable cox regression analyses of survival in female thyroid cancer

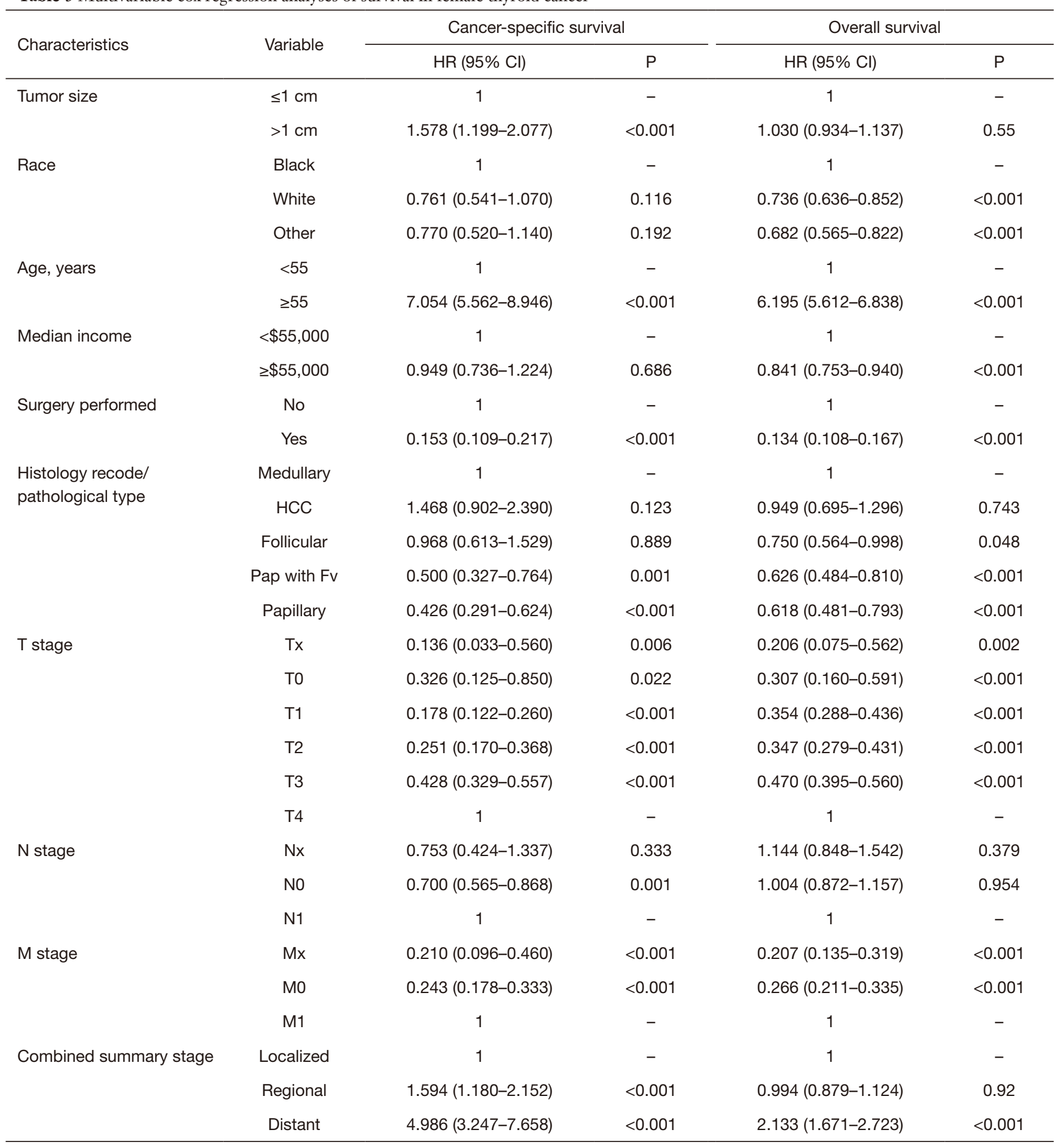

HCC, Hurthle cell carcinoma; Pap with Fv, papillary with follicular variant. 
$=0.89,95 \%$ CI: $0.853-0.933, \mathrm{P}<0.001)$. The risk of death was increased with T, $M$ stage upgrading. Similar results were seen in analysis of OS for male patients (Table 3 and Table S6). For CSS, the factors for female patients (Table 4 and Table S7) were tumor size ( $>1 v s . \leq 1 \mathrm{~cm}$ : $\mathrm{HR}=1.58$, 95\% CI: 1.199-2.077, $\mathrm{P}<0.001)$, age of diagnosis ( $<55$ vs. $\geq 55$ years old: HR $=7.05,95 \%$ CI: $5.562-8.946, \mathrm{P}<0.001$ ), surgery (versus not performed: HR $=0.15,95 \%$ CI: 0.109 0.217, $\mathrm{P}<0.001$ ), histology recode (versus medullary, HR $=0.75,95 \%$ CI: $0.696-0.809, \mathrm{P}<0.001)$ and the increased risk of death with upgrading of T, N, M and combined summary stage. In male patients, median income $(\geq \$ 55000$ $v s .<\$ 55,000$ : $\mathrm{HR}=0.74,95 \%$ CI: $0.574-0.953, \mathrm{P}=0.020$ ) had an additional impact compared with the female patients (Table 4 and Table S8). These findings implicated that the race, age of diagnosis, median income, surgery, tumor size, histology recode, T, N, M and combined summary stage contribute to the prognosis of thyroid cancer.

\section{Discussion}

In the present study, we found that male patients had larger tumor sizes than female patients. Besides, the tumor grade of male patients was worse than female patients at the time of diagnosis with thyroid cancer. Meanwhile, mean NR were 0.20 and 0.30 in female and male patients, respectively. Importantly, male patients had significantly poorer OS and CSS than female patients. We also found that male and female patients had different prognostic risk factors. However, unlike female patients, median income affected CSS for male patients. Whereas race had an impact on the OS but not on CSS for patients with thyroid cancer. Interestingly, clinical features stratification revealed, that only white patients and PTC patients had a significant sex difference in the CSS compared to the other races and histological types of thyroid cancer. However, this observation might be due to the insufficient number of cases in other subgroups after clinical characteristics stratification.

Our study showed that in comparison with other races, both male and female patients had worse OS among blacks. However, this observation is most likely arisen due to the number of interrelating factors, including genetic, environmental, lifestyle and relatively poor financial situation (25). Further the median income was mainly affected the OS of patients with thyroid cancer. Leboulleux et al. demonstrated that the number of positive LNs were related to the significantly higher 10-year risk of recurrence: $3 \%$ for $<5 \mathrm{LN}$ metastases (26). Whereas Nam et al. demonstrated that NR $>0.3$ was associated with higher rates of any site and nodal recurrence (27). Considering the previous findings, our results on the positive number and positive ratio of $\mathrm{LNs}$ in thyroid cancer patients supported the conclusion of male patients have worse prognosis.

The significant differences observed in the incidence as well as the prognosis of male and female patients with thyroid cancer remains unclear. Numerous studies have attempted to explain the sex differences in the thyroid cancer. A higher incidence of thyroid cancer in women is explained by the probable role of high estrogen levels, methylation of $\mathrm{X}$ chromosome promoter (28), overexpression and mutations of EZH2, KDM5C, and IL7R gene (29-31). Additionally, Hashimoto's thyroiditis (HT), which is more prevalent in women, has close association with thyroid cancer (32). Although the incidence of thyroid cancer is higher in women, the overall mutation burden is higher in men (33). The animal study has shown that testosterone promoted the progression of FTC in mice, which is consistent with the more aggressive form and poor prognosis of FTC observed in men (34). Further, TFRC over-expresses in women and is associated with tumor progression and poor prognosis (35). In addition, higher ESR1 expression with higher ESR ratio in female PTC patients were associated with the invasive prognostic factors and poorer OS (36). Our research provides evidence for systematically incorporating the sex differences into the paradigms for laboratory as well as the clinical cancer research, with the special emphasis on developing the personalized approaches for cutting-edge cancer treatment.

Widespread poor prognosis in male patients is observed across age and ethnicity. However, as age and ethnicity are permanent factors, diligent screening for thyroid cancer and more radical treatments in men is required.

The current study had some limitations. We were subjected to restrictions related to the SEER database, such as only one-third of the United States population could be covered, incomplete data collection (no data on smoking, drinking, family history, weight and height, and medical comorbidities), information inaccuracy and inconsistent tumor classification for the staging angle. These issues might have caused potential deviations in our analysis. Additionally, we did not evaluate the impact of social status on the prognosis of patients with thyroid cancer. 
Table 4 Multivariable cox regression analyses of survival in male thyroid cancer

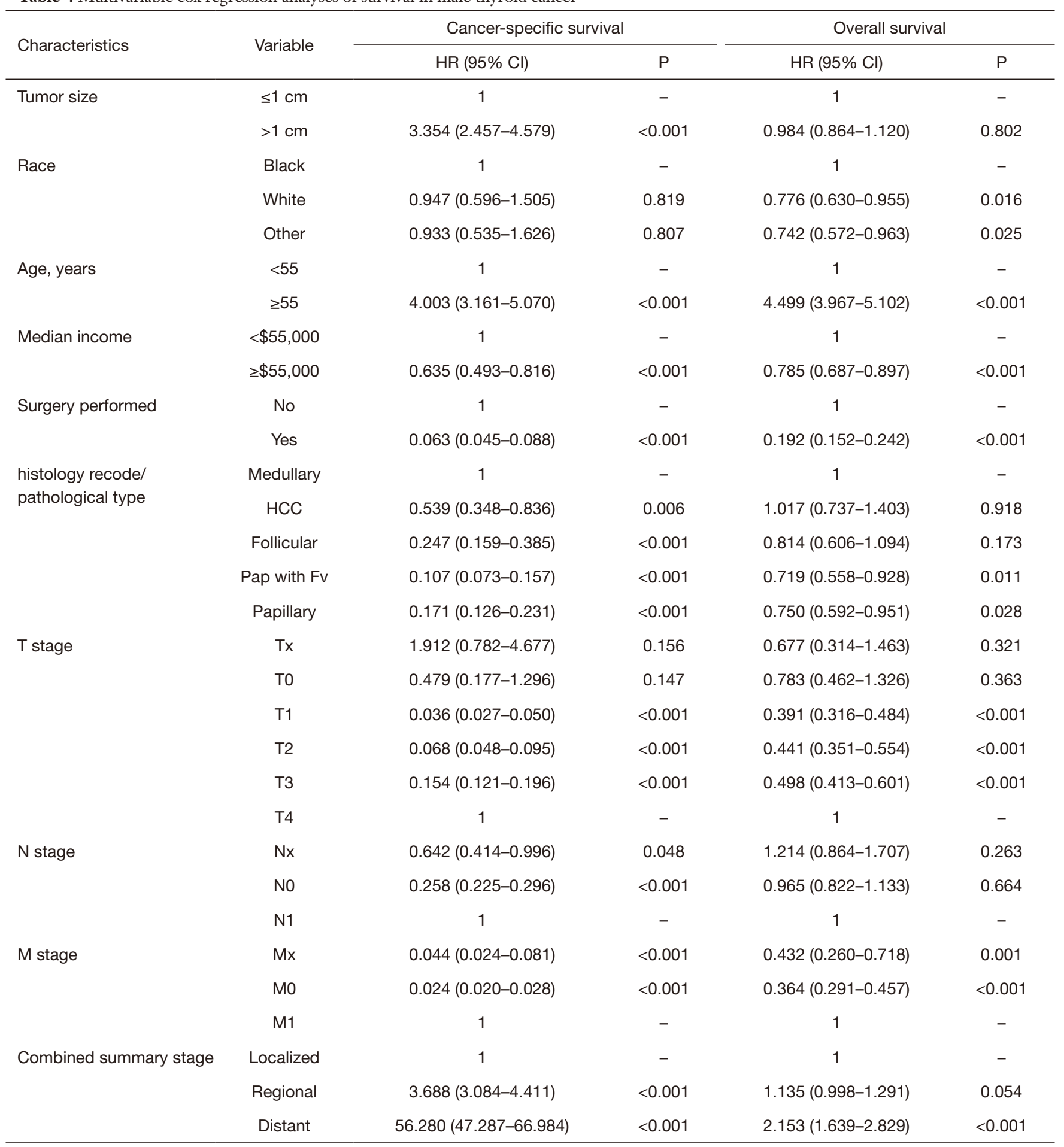

HCC, Hurthle cell carcinoma; Pap with Fv, papillary with follicular variant. 


\section{Conclusions}

To conclude, although thyroid cancer was more prevalent in women than men, at the time of diagnosis, male patients had larger tumors and higher TNM stage. Further, male patients had significantly poorer OS and CSS than female patients, which might not only due to the diagnostic bias. Additionally, this study showed that male and female patients had different prognostic risk factors and unlike in female patients, median income affected CSS of male patients. Lastly, race only had an impact on the OS but not on the CSS of patients suffering with thyroid cancer.

\section{Acknowledgments}

We would like to thank the SEER databases for providing important data and all the reviewers who participated in the review and MJEditor for its linguistic assistance during the preparation of this manuscript.

Funding: This work was supported by the National Natural Science Foundation of China (Grant No. 81672885) and the Innovative Foundation for graduate students of Hunan Province (Grant No. 2020zzts259).

\section{Footnote}

Reporting Checklist: The authors have completed the STROBE reporting checklist. Available at https://dx.doi. org/10.21037/gs-21-545

Conflicts of Interest: All authors have completed the ICMJE uniform disclosure form (available at https://dx.doi. org/10.21037/gs-21-545). XL serves as an unpaid Associate Editor of Gland Surgery from March 2018 to February 2023. The other authors have no conflicts of interest to declare.

Ethical Statement: The authors are accountable for all aspects of the work in ensuring that questions related to the accuracy or integrity of any part of the work are appropriately investigated and resolved. The present study conformed to the provisions of the Declaration of Helsinki (as revised in 2013).

Open Access Statement: This is an Open Access article distributed in accordance with the Creative Commons Attribution-NonCommercial-NoDerivs 4.0 International License (CC BY-NC-ND 4.0), which permits the non- commercial replication and distribution of the article with the strict proviso that no changes or edits are made and the original work is properly cited (including links to both the formal publication through the relevant DOI and the license). See: https://creativecommons.org/licenses/by-nc$\mathrm{nd} / 4.0 /$.

\section{References}

1. Siegel RL, Miller KD, Jemal A. Cancer statistics, 2020. CA Cancer J Clin 2020;70:7-30.

2. Cabanillas ME, McFadden DG, Durante C. Thyroid cancer. Lancet 2016;388:2783-95.

3. Miller KD, Fidler-Benaoudia M, Keegan TH, et al. Cancer statistics for adolescents and young adults, 2020. CA Cancer J Clin 2020;70:443-59.

4. Davies L, Welch HG. Current thyroid cancer trends in the United States. JAMA Otolaryngol Head Neck Surg 2014;140:317-22.

5. Lim H, Devesa SS, Sosa JA, et al. Trends in Thyroid Cancer Incidence and Mortality in the United States, 1974-2013. JAMA 2017;317:1338-48.

6. Li M, Dal Maso L, Vaccarella S. Global trends in thyroid cancer incidence and the impact of overdiagnosis. Lancet Diabetes Endocrinol 2020;8:468-70.

7. Haugen BR, Alexander EK, Bible KC, et al. 2015 American Thyroid Association Management Guidelines for Adult Patients with Thyroid Nodules and Differentiated Thyroid Cancer: The American Thyroid Association Guidelines Task Force on Thyroid Nodules and Differentiated Thyroid Cancer. Thyroid 2016;26:1-133.

8. Maniakas A, Dadu R, Busaidy NL, et al. Evaluation of Overall Survival in Patients With Anaplastic Thyroid Carcinoma, 2000-2019. JAMA Oncol 2020;6:1397-404.

9. Kitahara CM, Sosa JA. Understanding the ever-changing incidence of thyroid cancer. Nat Rev Endocrinol 2020;16:617-8.

10. Du L, Zhao Z, Zheng R, et al. Epidemiology of Thyroid Cancer: Incidence and Mortality in China, 2015. Front Oncol 2020;10:1702.

11. Milano AF. Thyroid Cancer: 20-Year Comparative Mortality and Survival Analysis of Six Thyroid Cancer Histologic Subtypes by Age, Sex, Race, Stage, Cohort Entry Time-Period and Disease Duration (SEER*Stat 8.3.2) A Systematic Review of 145,457 Cases for Diagnosis Years 1993-2013. J Insur Med 2018;47:143-58.

12. Wang W, Bai N, Ouyang Q, et al. Prediction of level V metastases in papillary thyroid microcarcinoma: a single 
center analysis. Gland Surg 2020;9:899-906.

13. Wang W, Yang Z, Ouyang Q. A nomogram to predict skip metastasis in papillary thyroid cancer. World J Surg Oncol 2020;18:167.

14. Guo K, Wang Z. Risk factors influencing the recurrence of papillary thyroid carcinoma: a systematic review and metaanalysis. Int J Clin Exp Pathol 2014;7:5393-403.

15. Bian F, Li C, Han D, et al. Competing-Risks Model for Predicting the Postoperative Prognosis of Patients with Papillary Thyroid Adenocarcinoma Based on The Surveillance, Epidemiology, and End Results (SEER) Database. Med Sci Monit 2020;26:e924045.

16. Liu C, Chen T, Zeng W, et al. Reevaluating the prognostic significance of male gender for papillary thyroid carcinoma and microcarcinoma: a SEER database analysis. Sci Rep 2017;7:11412.

17. Kruijff S, Petersen JF, Chen P, et al. Patterns of structural recurrence in papillary thyroid cancer. World J Surg 2014;38:653-9.

18. Nilubol N, Zhang L, Kebebew E. Multivariate analysis of the relationship between male sex, disease-specific survival, and features of tumor aggressiveness in thyroid cancer of follicular cell origin. Thyroid 2013;23:695-702.

19. Oyer SL, Smith VA, Lentsch EJ. Reevaluating the prognostic significance of age in differentiated thyroid cancer. Otolaryngol Head Neck Surg 2012;147:221-6.

20. Grogan RH, Kaplan SP, Cao H, et al. A study of recurrence and death from papillary thyroid cancer with 27 years of median follow-up. Surgery 2013;154:1436-46; discussion 1446-7.

21. Mao W, Zhang Z, Huang X, et al. Marital Status and Survival in Patients with Penile Cancer. J Cancer 2019;10:2661-9.

22. Perrier ND, Brierley JD, Tuttle RM. Differentiated and anaplastic thyroid carcinoma: Major changes in the American Joint Committee on Cancer eighth edition cancer staging manual. CA Cancer J Clin 2018;68:55-63.

23. Nam SH, Bae MR, Roh JL, et al. A comparison of the 7 th and 8th editions of the AJCC staging system in terms of predicting recurrence and survival in patients with papillary thyroid carcinoma. Oral Oncol 2018;87:158-64.

24. Austin PC. Optimal caliper widths for propensity-score matching when estimating differences in means and differences in proportions in observational studies. Pharm Stat 2011;10:150-61.

25. Keane E, Francis EC, Catháin ÉÓ, et al. The role of race in thyroid cancer: systematic review. J Laryngol Otol
2017;131:480-6.

26. Leboulleux S, Rubino C, Baudin E, et al. Prognostic factors for persistent or recurrent disease of papillary thyroid carcinoma with neck lymph node metastases and/ or tumor extension beyond the thyroid capsule at initial diagnosis. J Clin Endocrinol Metab 2005;90:5723-9.

27. Nam SH, Roh JL, Gong G, et al. Nodal Factors Predictive of Recurrence After Thyroidectomy and Neck Dissection for Papillary Thyroid Carcinoma. Thyroid 2018;28:88-95.

28. Sousa A, Ferreira M, Oliveira C, et al. Gender Differential Transcriptome in Gastric and Thyroid Cancers. Front Genet 2020;11:808.

29. Kim KH, Roberts CW. Targeting EZH2 in cancer. Nat Med 2016;22:128-34.

30. Tricarico R, Nicolas E, Hall MJ, et al. X- and Y-Linked Chromatin-Modifying Genes as Regulators of SexSpecific Cancer Incidence and Prognosis. Clin Cancer Res 2020;26:5567-78.

31. Kim MJ, Choi SK, Hong SH, et al. Oncogenic IL7R is downregulated by histone deacetylase inhibitor in esophageal squamous cell carcinoma via modulation of acetylated FOXO1. Int J Oncol 2018;53:395-403.

32. Zeng R, Lyu Y, Niu H, et al. FoxP3 promotes lymph node metastasis in patients with papillary thyroid carcinoma complicated with Hashimoto's thyroiditis. Transl Cancer Res 2020;9:1337-50.

33. Credendino SC, Neumayer C, Cantone I. Genetics and Epigenetics of Sex Bias: Insights from Human Cancer and Autoimmunity. Trends Genet 2020;36:650-63.

34. Zhang LJ, Xiong Y, Nilubol N, et al. Testosterone regulates thyroid cancer progression by modifying tumor suppressor genes and tumor immunity. Carcinogenesis 2015;36:420-8.

35. Yang J, Gong Y, Yan S, et al. Association between TERT promoter mutations and clinical behaviors in differentiated thyroid carcinoma: a systematic review and meta-analysis. Endocrine 2020;67:44-57.

36. Yi JW, Kim SJ, Kim JK, et al. Upregulation of the ESR1 Gene and ESR Ratio (ESR1/ESR2) is Associated with a Worse Prognosis in Papillary Thyroid Carcinoma: The Impact of the Estrogen Receptor $\alpha / \beta$ Expression on Clinical Outcomes in Papillary Thyroid Carcinoma Patients. Ann Surg Oncol 2017;24:3754-62.

Cite this article as: Li P, Ding Y, Liu M, Wang W, Li X. Sex disparities in thyroid cancer: a SEER population study. Gland Surg 2021;10(12):3200-3210. doi: 10.21037/gs-21-545 
SEER ${ }^{\star}$ Stat software to collect patients from the SEER database who were coded as the primary site thyroid from 2004-2018

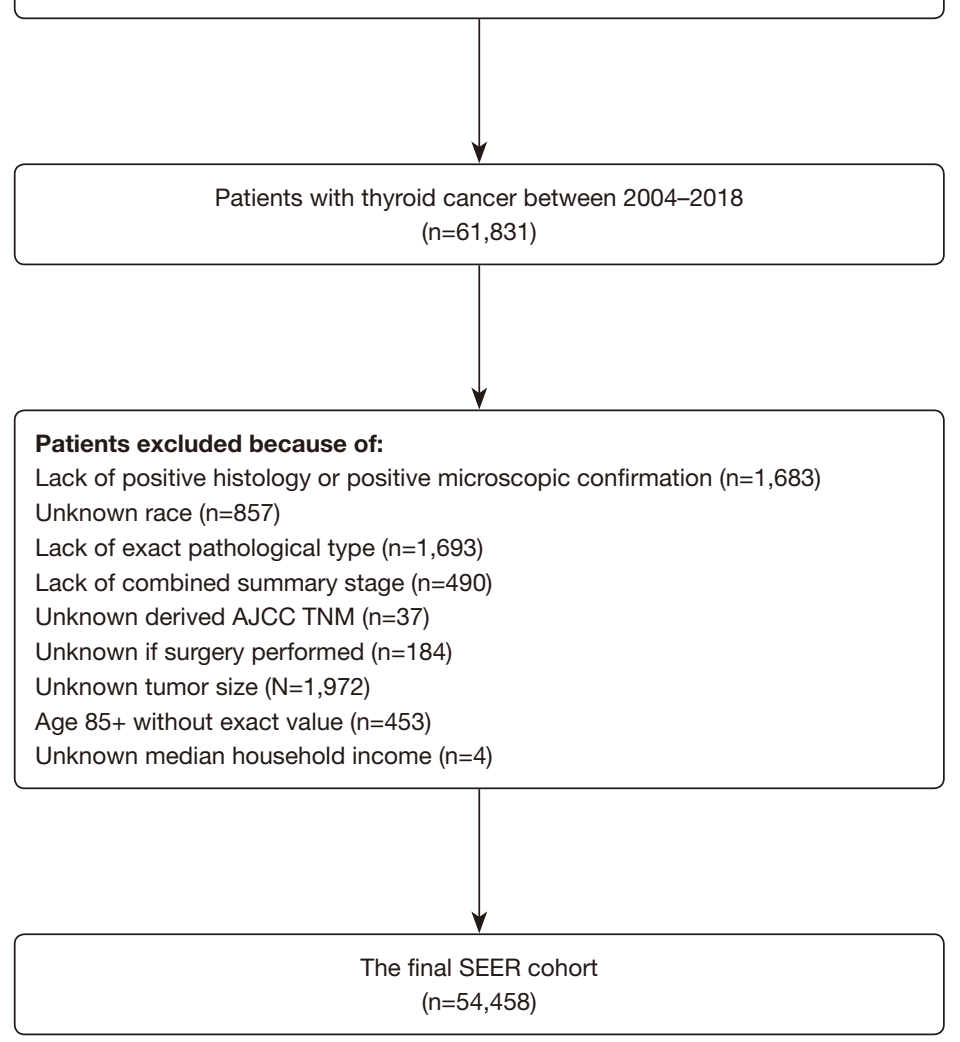

Figure S1 Flowchart of the SEER cohort. 
Table S1 Univariable and multivariable cox regression analyses of overall survival in the SEER cohort

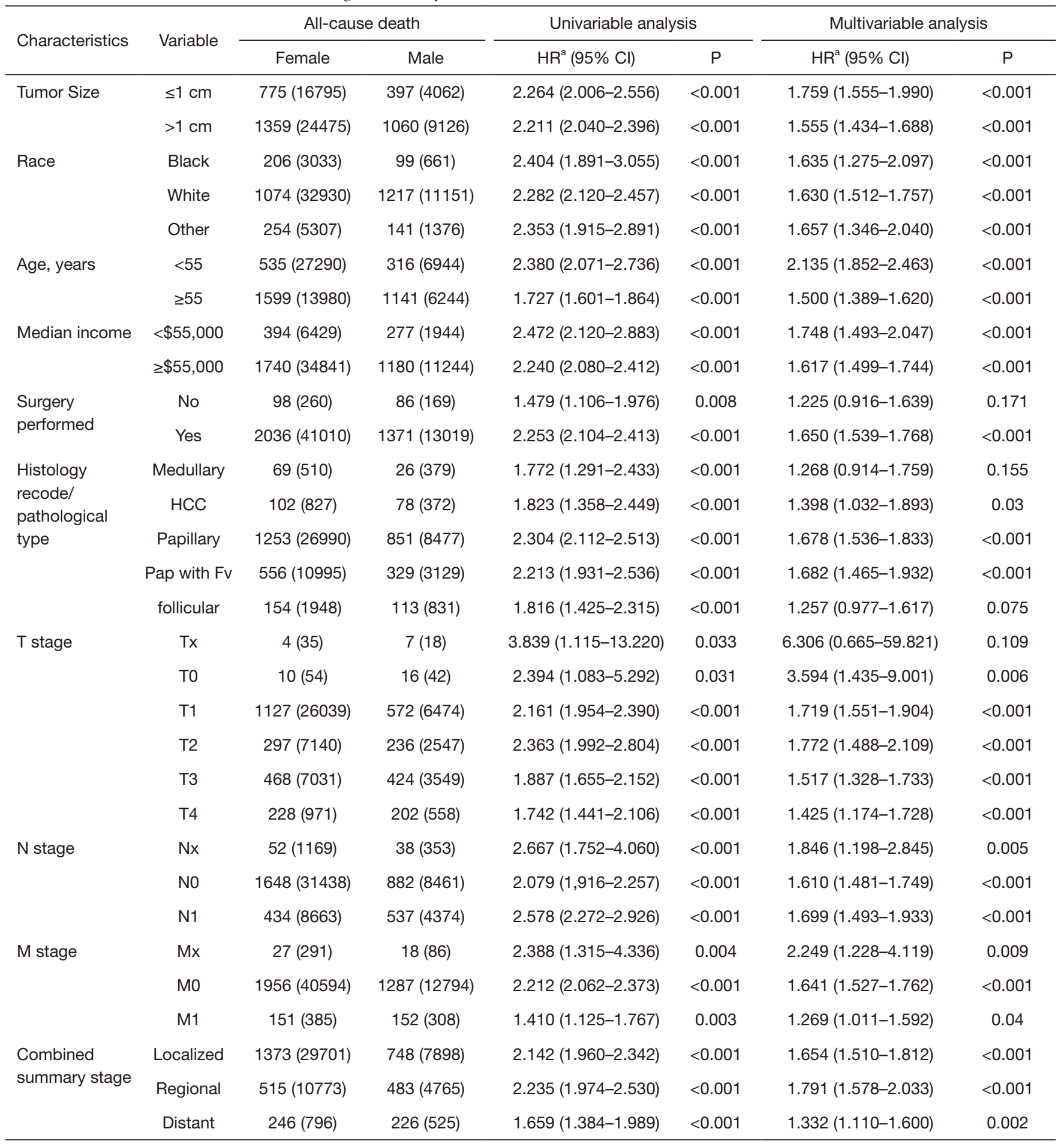

\footnotetext{
${ }^{a}$, males versus females. HCC, Hurthle cell carcinoma; Pap with Fv, papillary with follicular variant.
} 
Table S2 Univariable and multivariable cox regression analyses of cancer-specific survival in the SEER cohort

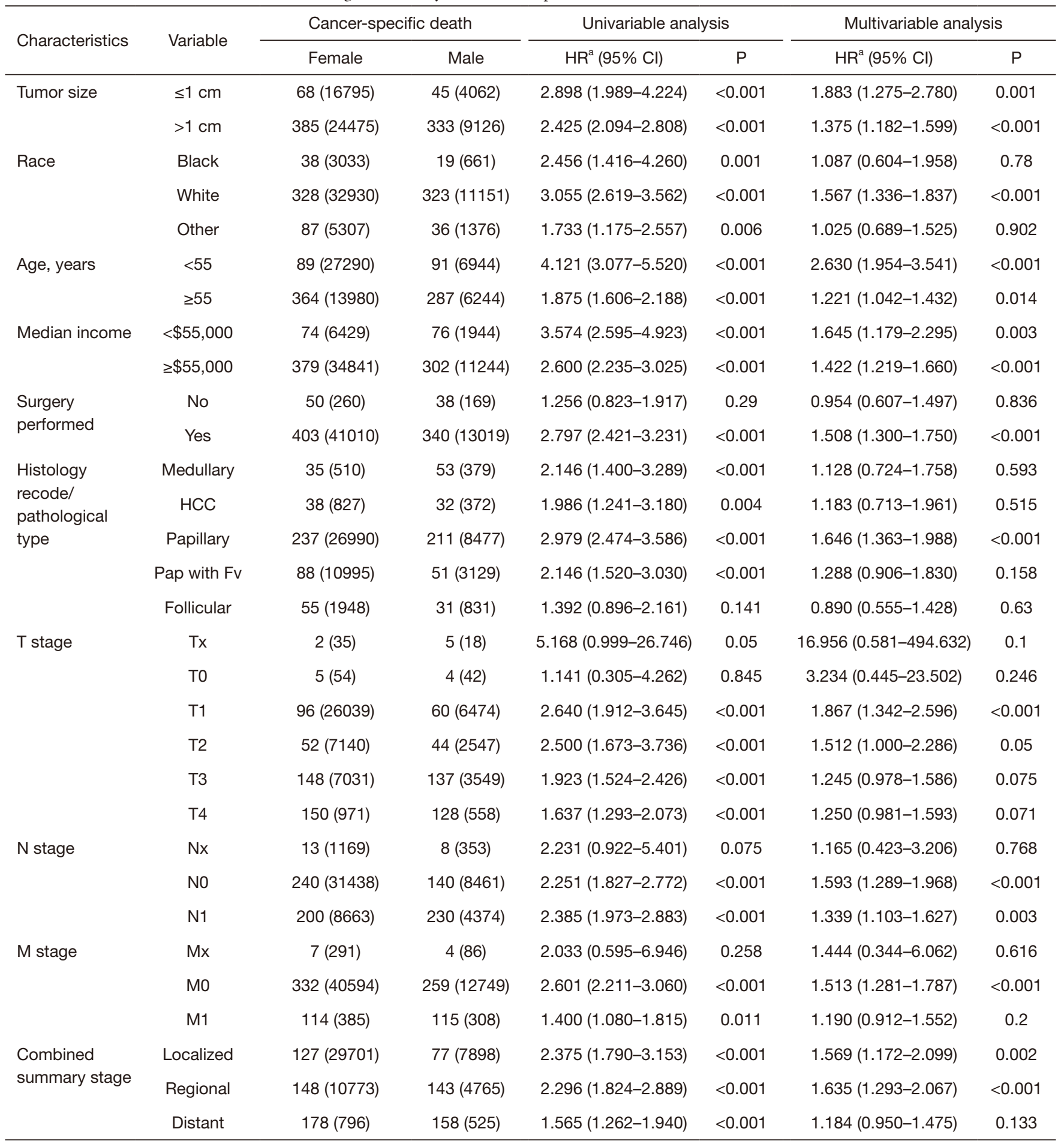

${ }^{a}$, males versus females. HCC, Hurthle cell carcinoma; Pap with Fv, papillary with follicular variant. 
Table S3 Sex differences in nodal ratio

\begin{tabular}{|c|c|c|c|c|c|c|c|}
\hline Sex & \multicolumn{3}{|c|}{ Regional nodes examined } & \multicolumn{3}{|c|}{ Regional nodes positive } & $\begin{array}{l}\text { Nodal ratio } \\
\text { Mean } \pm \text { SD }\end{array}$ \\
\hline Female $(n=21825)$ & 8.584 & $1-90$ & 3 & 2.045 & $0-67$ & 0 & $0.192 \pm 0.312$ \\
\hline Male $(n=7256)$ & 13.408 & $1-90$ & 5 & 4.013 & $0-65$ & 1 & $0.297 \pm 0.351$ \\
\hline
\end{tabular}


Table S4 Baseline characteristics of the post-PSM cohort

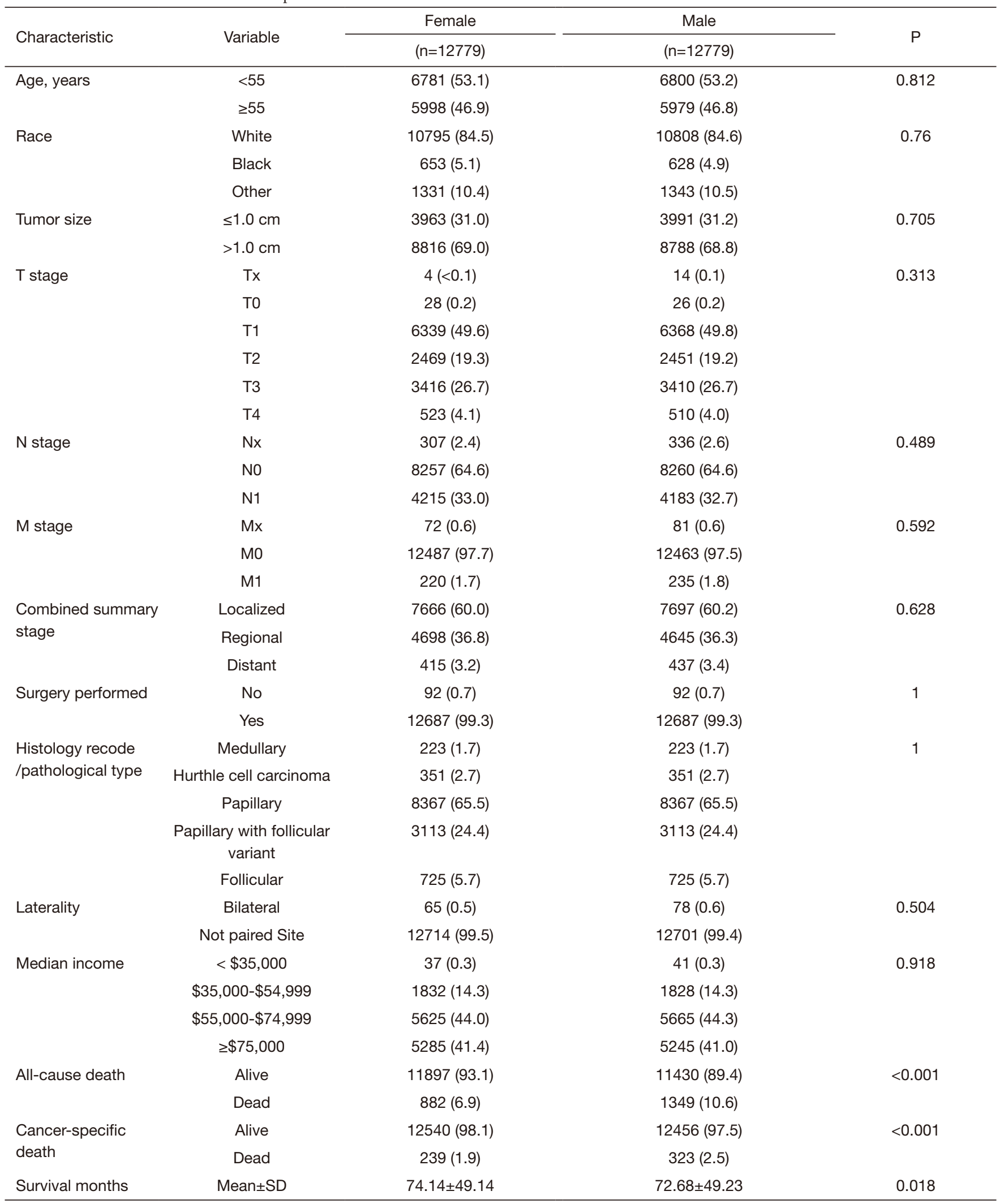



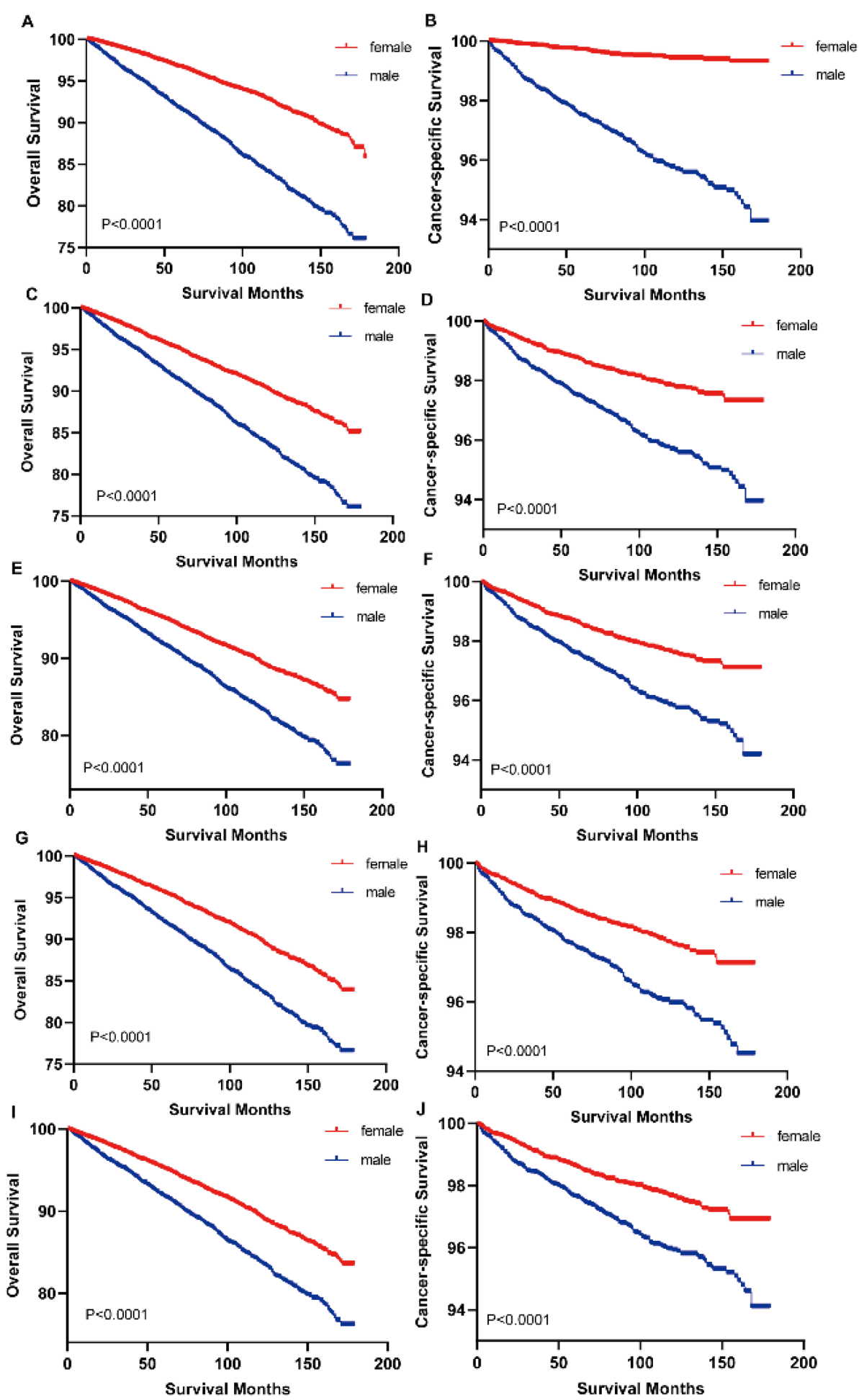

Figure S2 Overall and cancer-specific survival curves after propensity score matching including different factors, one-to-one match. (A,B) Only race and age of diagnosis were included in matching. (C,D) Race, age of diagnosis and combined summary stage included. (E,F) Race, age of diagnosis, combined summary stage and histology recode included. $(\mathrm{G}, \mathrm{H})$ Race, age of diagnosis, combined summary stage, histology re-code and tumor size included. $(I, J)$ Race, age of diagnosis, combined summary stage, histology re-code, tumor size, and surgery performed or not included. K-M curves were compared using log-rank test, $\mathrm{P}<0.001$, respectively. 
Table S5 Univariable and multivariable cox regression analyses of overall survival in female thyroid cancer

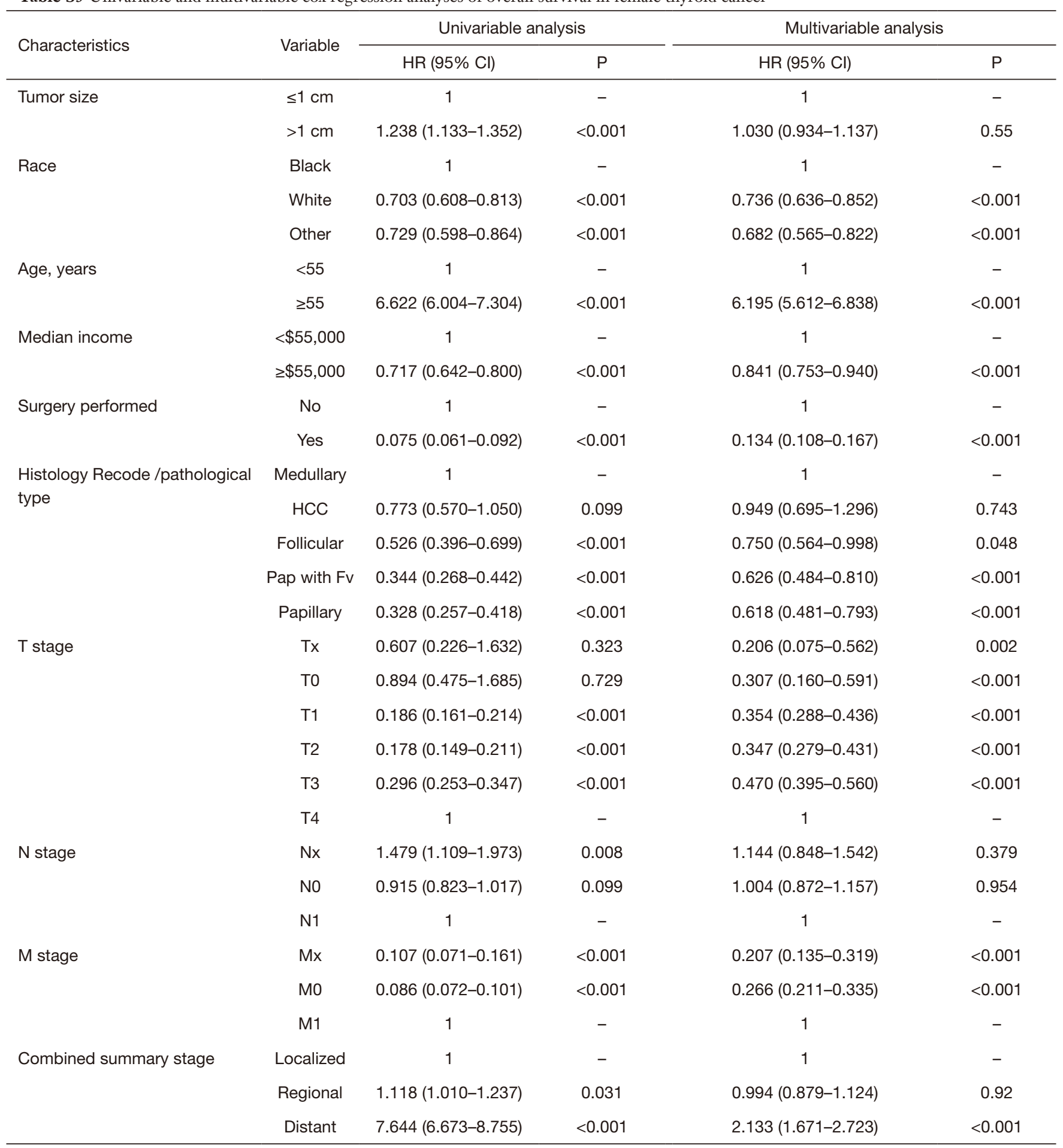

HCC, Hurthle cell carcinoma; Pap with Fv, papillary with follicular variant. 
Table S6 Univariable and multivariable cox regression analyses of overall survival in male thyroid cancer

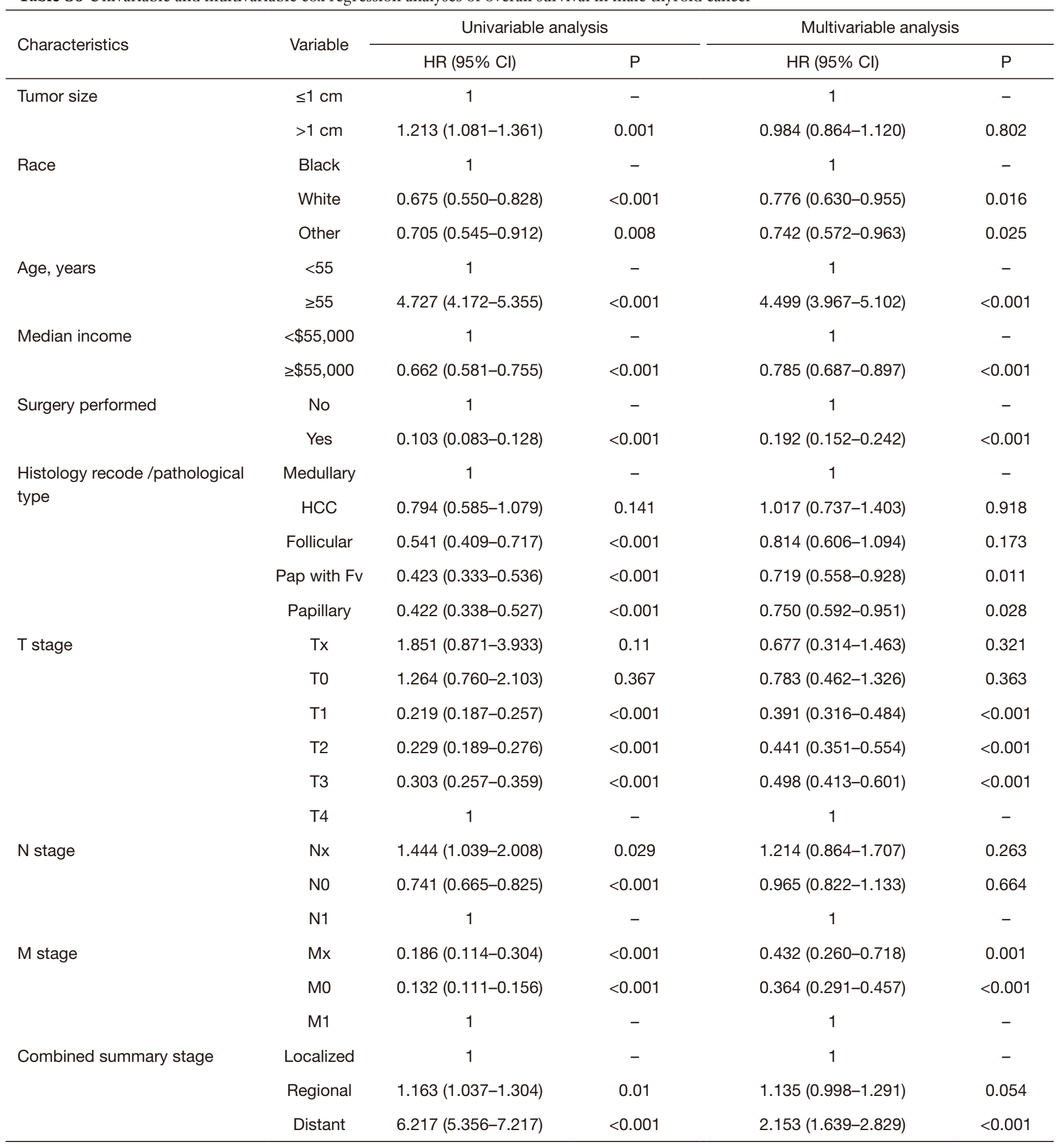

HCC, Hurthle cell carcinoma; Pap with Fv, papillary with follicular variant. 
Table S7 Univariable and multivariable cox regression analyses of cancer-specific survival in female thyroid cancer

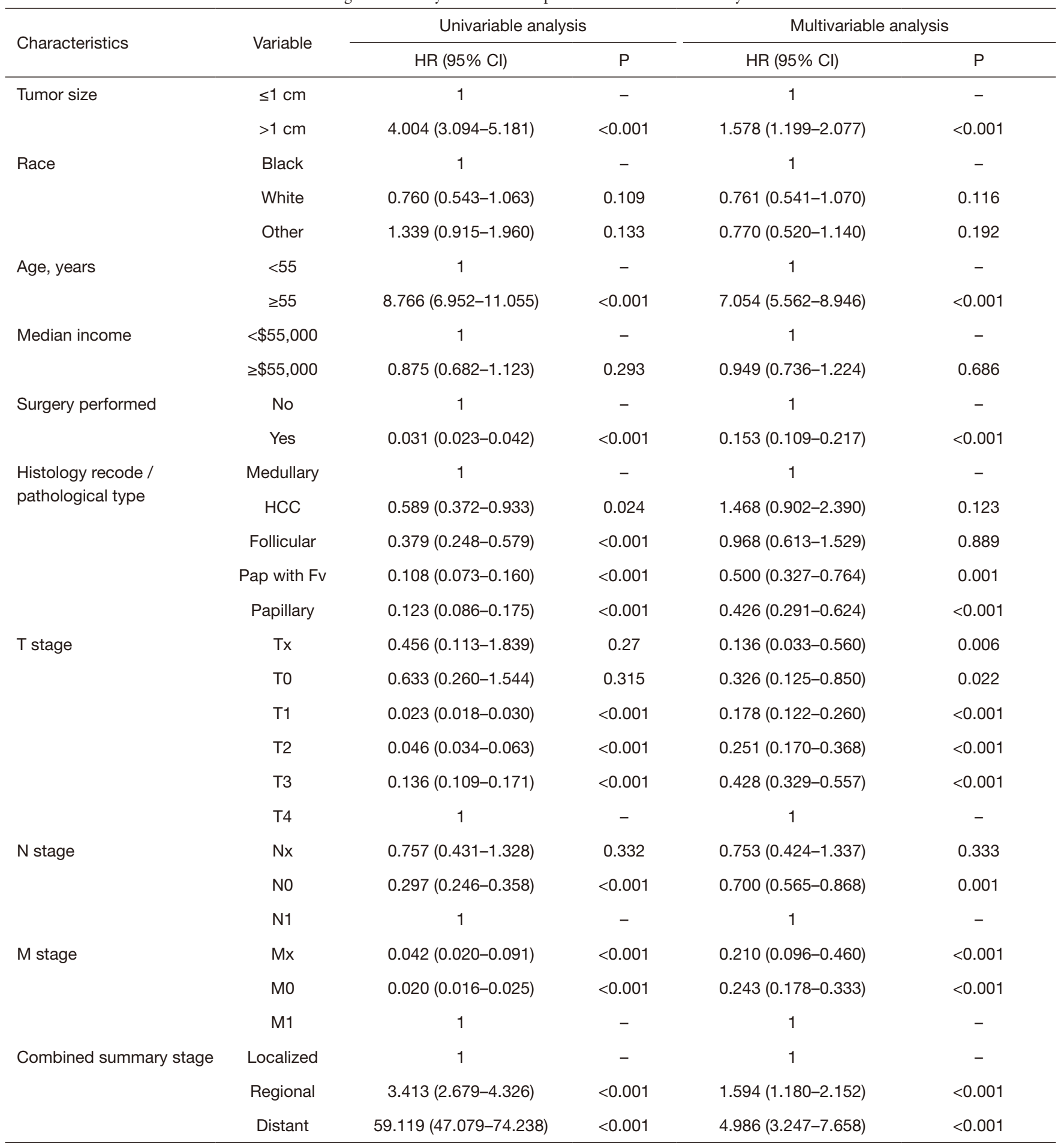

HCC, Hurthle cell carcinoma; Pap with Fv, papillary with follicular variant. 
Table S8 Univariable and multivariable cox regression analyses of cancer-specific survival in male thyroid cancer

\begin{tabular}{|c|c|c|c|c|c|}
\hline Characteristics & Variable & \multicolumn{2}{|c|}{ Univariable analysis } & \multicolumn{2}{|c|}{ Multivariable analysis } \\
\hline \multirow[t]{2}{*}{ Tumor size } & $\leq 1 \mathrm{~cm}$ & 1 & - & 1 & - \\
\hline & $>1 \mathrm{~cm}$ & 3.354 (2.457-4.579) & $<0.001$ & $1.705(1.380-2.106)$ & $<0.001$ \\
\hline \multirow[t]{2}{*}{ Race } & Black & 1 & - & 1 & - \\
\hline & Other & $0.933(0.535-1.626)$ & 0.807 & $0.814(0.591-1.122)$ & 0.209 \\
\hline \multirow[t]{2}{*}{ Age, years } & $<55$ & 1 & - & 1 & - \\
\hline & $\geq 55$ & $4.003(3.161-5.070)$ & $<0.001$ & $3.392(2.661-4.325)$ & $<0.001$ \\
\hline Median income & $<\$ 55,000$ & 1 & - & 1 & - \\
\hline Surgery performed & Yes & $0.063(0.045-0.088)$ & $<0.001$ & $0.272(0.188-0.395)$ & $<0.001$ \\
\hline \multirow{5}{*}{$\begin{array}{l}\text { Histology recode /pathological } \\
\text { type }\end{array}$} & Medullary & 1 & - & 1 & - \\
\hline & $\mathrm{HCCv}$ & $0.539(0.348-0.836)$ & 0.006 & $1.263(0.901-1.770)$ & 0.175 \\
\hline & Follicular & $0.247(0.159-0.385)$ & $<0.001$ & $0.831(0.601-1.150)$ & 0.264 \\
\hline & Pap with Fv & $0.107(0.073-0.157)$ & $<0.001$ & $0.437(0.325-0.588)$ & $<0.001$ \\
\hline & Papillary & $0.171(0.126-0.231)$ & $<0.001$ & $0.459(0.355-0.593)$ & $<0.001$ \\
\hline \multirow[t]{2}{*}{ T stage } & Tx & $1.912(0.782-4.677)$ & 0.156 & $0.315(0.146-0.680)$ & 0.003 \\
\hline & TO & $0.479(0.177-1.296)$ & 0.147 & $0.475(0.232-0.973)$ & 0.042 \\
\hline \multirow{2}{*}{$\mathrm{N}$ stage } & NO & $0.258(0.225-0.296)$ & $<0.001$ & $0.753(0.638-0.889)$ & 0.001 \\
\hline & $\mathrm{N} 1$ & 1 & - & 1 & - \\
\hline \multirow[t]{3}{*}{ M stage } & $M x$ & $0.044(0.024-0.081)$ & $<0.001$ & $0.240(0.129-0.446)$ & $<0.001$ \\
\hline & MO & $0.024(0.020-0.028)$ & $<0.001$ & $0.256(0.204-0.320)$ & $<0.001$ \\
\hline & M1 & 1 & - & 1 & - \\
\hline \multirow[t]{3}{*}{ Combined summary stage } & Localized & 1 & - & 1 & - \\
\hline & Regional & $3.688(3.084-4.411)$ & $<0.001$ & $1.826(1.456-2.291)$ & $<0.001$ \\
\hline & Distant & $56.280(47.287-66.984)$ & $<0.001$ & $5.129(3.700-7.110)$ & $<0.001$ \\
\hline
\end{tabular}

HCC, Hurthle cell carcinoma; Pap with Fv, papillary with follicular variant. 